\title{
Resistência Parcial à Brusone em Somaclones da Cultivar de Arroz CICA-8
}

\author{
Leila G. Araújo \& Anne S. Prabhu \\ 'Embrapa Arroz e Feijão, Cx. Postal 179, CEP 75375-000, Santo Antônio de Goiás, GO, fax (062) 533-2100, e-mails: \\ leilag@cnpaf.embrapa.br; prabhu@cnpaf.embrapa.br
}

(Aceito para publicação em 23/05/2004)

Autor para correspondência: Leila G. Araújo

ARAÚJO, L.G. \& PRABHU, A.S. Resistência parcial à brusone em somaclones da cultivar de arroz CICA-8. Fitopatologia Brasileira 29:394398. 2004.

\section{RESUMO}

A obtenção de novas fontes de resistência à brusone é requerimento básico para melhoramento do arroz (Oryza sativa). $\mathrm{O}$ objetivo do trabalho foi avaliar, para resistência à brusone, 39 somaclones da cultivar CICA-8, desenvolvidos a partir de calos de panículas imaturas. Os somaclones, nas gerações avançadas de $R_{5}$ a $\mathrm{R}_{7}$, foram avaliados sob condições naturais de infecção e em testes de inoculação artificial em casa de vegetação, utilizando cinco isolados, pertencentes a quatro patótipos (ID-14, II-1, IB-1 e IB-45) de Pyricularia grisea. No viveiro de brusone os somaclones apresentaram diferentes reações à doença. Nos testes de inoculação os somaclones mostraram interação diferencial com os isolados do patógeno. Dois isolados altamente virulentos a cinco somaclones foram selecionados para determinar a resistência parcial. Não houve interação significativa entre genótipos e isolados para o índice de resistência parcial determinado com base no número de lesões $/ \mathrm{cm}^{2}$ de folha. Quatro somaclones mostraram graus significativamente maiores de resistência parcial à brusone quando comparados à cultivar parental CICA-8.

Palavras-chave adicionais: Magnaporthe grisea, Oryza sativa, cultura de tecido, variação somaclonal.

\begin{abstract}
Partial resistance to blast in somaclones of rice cultivar CICA-8 The development of rice blast resistance sources is a basic requirement for rice (Oryza sativa) breeding. The main objective of this investigation was to evaluate somaclones of rice cultivar CICA8 , developed from callus cultures of immature panicles for blast resistance. Rice blast in 39 somaclones was assessed in the advanced generations from $\mathrm{R}_{5}$ to $\mathrm{R}_{7}$, in the blast nursery under natural conditions of infection and in greenhouse inoculation tests, using five isolates pertaining to four pathotypes (ID-14, II-1, IB-1 and IB-45) of
\end{abstract}

ABSTRACT
Pyricularia grisea. In the rice blast nursery, somaclones exhibited differences in disease reactions. In inoculation tests, somaclones showed differential interaction between isolates of the pathogen and genotypes. Two isolates highly virulent to five somaclones including CICA-8 and CO 39 were selected to determine the partial resistance. There was no significant interaction between isolates and somaclones for partial resistance index, determined based on leaf lesion number per $\mathrm{cm}^{2}$. Four somaclones showed significantly higher degree of partial resistance when compared with the parent cultivar CICA-8.

\section{INTRODUÇÃO}

A cultivar de arroz (Oryza sativa L.) CICA-8 foi originalmente considerada resistente à brusone [Pyricularia grisea (Cooke) Sacc. Magnaporthe grisea (Hebert) Barr]. Esta cultivar foi introduzida do Centro Internacional de Agricultura Tropical (CIAT), Colômbia, tendo sido a mais plantada em vários estados do Brasil, na década de 80 . A resistência desta cultivar à brusone foi superada nos Estados de Santa Catarina, São Paulo, Minas Gerais e Tocantins sendo, a seguir, substituída por outras cultivares. A base genética das cultivares irrigadas é estreita, sendo necessário a identificação de outras fontes de resistência à brusone. A cultura de tecido é uma das opções para indução de variabilidade genética e seleção de mutantes resistentes nas plantas de arroz.

A variação somaclonal tem sido utilizada em várias culturas, incluindo o arroz, para a produção de plantas com características desejáveis não existentes na natureza (Mandal et al., 2000). Algumas características morfológicas e agronômicas como coloração da arista, tipo de grão, altura, perfilhamento, tipo de planta, floração, massa dos grãos e rendimento, obtidas por variação somaclonal, demonstraram ser herdáveis e controlada por um ou poucos genes no arroz (Mandal et al., 2000). A resistência a doenças é uma das características mais importantes encontradas na variação somaclonal em arroz (Xie et al., 1990) sendo produzidos mutantes genéticos tanto dominantes como recessivos (Fukui, 1983). No Brasil foram desenvolvidos somaclones com resistência vertical e parcial à brusone a partir de cultivares suscetíveis de arroz como IAC 47, Araguaia, Bluebelle, Basmati-370 e Metica-1 (Araújo et al., 1997, 2000; Araújo \& Prabhu, 2001a, b; Araújo et al., 2001; Araújo \& Prabhu, 2002).

A resistência vertical ou específica é controlada por genes maiores e não é efetiva contra todos os patótipos do patógeno (Plank, 1975). Por outro lado, a resistência parcial é caracterizada por uma reação de suscetibilidade, com baixa 
Resistência parcial à brusone em somaclones da cultivar...

severidade de doença, e de herança quantitativa (Parlevliet \& Ommeren, 1975). A resistência parcial foi menos utilizada nos programas de melhoramento embora seja encontrada em maior disponibilidade nas cultivares (Ribeiro do Vale et al., 2001). A seleção para resistência parcial no campo é dificultada devido ao efeito epistático de genes maiores, sendo recomendada a sua avaliação em casa de vegetação utilizando-se um isolado virulento a todos os genótipos (Yeh \& Bonman, 1986; Roumen, 1992).

O objetivo do presente trabalho foi avaliar o grau de resistência parcial nos somaclones da cultivar CICA-8.

\section{MATERIAL E MÉTODOS}

No presente trabalho foram utilizados somaclones obtidos da cultivar de arroz CICA-8, previamente desenvolvidos no laboratório de cultura de tecidos da Embrapa Arroz e Feijão, conforme a metodologia utilizada para desenvolvimento de somaclones da cultivar Metica-1 (Araújo \& Prabhu, 2001b).

Trinta e nove somaclones $\mathrm{R}_{5}, \mathrm{R}_{6}$ e $\mathrm{R}_{7}$ e a cultivar CICA8 foram avaliados no viveiro de brusone. Para obtenção de alta pressão de doença, os plantios foram feitos em canteiros (viveiro de brusone) em linhas de $0,5 \mathrm{~m}$ de comprimento espaçadas $0,10 \mathrm{~m}$ e com densidade de semeadura de 200 sementes $/ \mathrm{m}$. O solo foi adubado no plantio com $250 \mathrm{~kg} / \mathrm{ha} \mathrm{da}$ fórmula 4-30-16 e com $125 \mathrm{~kg} / \mathrm{ha}$ de $\mathrm{N}$ (sulfato de amônio). Uma bordadura composta pela mistura de cultivares suscetíveis foi estabelecida 30 dias antes do plantio a fim de induzir a epidemia da doença. A avaliação da brusone foi realizada 34 dias após o plantio utilizando-se uma escala de notas de 0-9 (International Rice Research Institute, 1988).

Em condições de casa de vegetação, os 39 somaclones $\mathrm{R}_{6}$ foram avaliados com cinco isolados de $P$. grisea, sendo um obtido da cultivar Metica-1 (MtPy), um da cultivar CICA-8 (CiPy), dois dos somaclones das cultivares Metica-1 (ScMtPy) e CICA-8 ( ScCiPy), e um da cultivar Epagri 108 ( EpPy). Cada bandeja (30x10x15 cm) com $3 \mathrm{~kg}$ de solo foi adubada, por ocasião do plantio, com $5 \mathrm{~g}$ de NPK (4-30-16), $1 \mathrm{~g}$ de sulfato de zinco e $2 \mathrm{~g}$ de sulfato de amônio. Foi feita uma adubação de cobertura, 20 dias após a semeadura, com $2 \mathrm{~g}$ de sulfato de amônio por bandeja. Foram semeados oito genótipos por bandeja, totalizando cinco bandejas por isolado. Em outra bandeja foram semeadas oito cultivares diferenciadoras internacionais (Dular, Kanto 51, NP125, Raminad Str 3, Usen, Zenith, Caloro e Sha-tio-tsão), as quais foram inoculadas com cada um dos isolados para a identificação dos patótipos. As plantas foram inoculadas aos 22 dias após a emergência, com uma suspensão de esporos contendo $3 \times 10^{5}$ conídios $/ \mathrm{ml}$ conforme a metodologia de Prabhu et al. (1992). A severidade de brusone nas folhas foi avaliada nove dias após a inoculação, utilizando-se uma escala de seis graus $(0,1,3,5,7$ e 9$)$ de acordo com Leung et al. (1988). As plantas que apresentaram graus de 0 a 3 foram consideradas resistentes ou incompatíveis e, de 5 a 9, suscetíveis ou compatíveis. Os patótipos foram identificados com base nas reações das oito diferenciadoras internacionais, de acordo com Atkins et al. (1967). Dois isolados altamente virulentos a cinco somaclones foram selecionados para determinar a resistência parcial.

A resistência parcial à brusone foi avaliada em sete genótipos, incluindo CICA-8, CO 39 e cinco somaclones que apresentaram reação suscetível aos isolados $C i P y$ e $S c C i P y$. Foi utilizado o delineamento de blocos ao acaso com cinco repetições, em um esquema de parcelas subdivididas. As parcelas principais consistiram dos isolados e as subparcelas dos genótipos. As plantas foram inoculadas separadamente com cada um dos isolados, em casa de vegetação, utilizando a mesma metodologia de inoculação descrita anteriormente. Os parâmetros de avaliação incluíram o número de lesões $/ \mathrm{cm}^{2} \mathrm{de}$ folha e a severidade baseada na porcentagem de área foliar afetada. A severidade da brusone nas folhas foi avaliada utilizando uma escala de dez graus (Notteghem, 1981). O índice de resistência parcial (IRP) foi calculado em relação à cultivar CO 39 utilizada como testemunha suscetível.

Foi realizada a análise de variância do IRP e a comparação de médias foi feita pelo teste de Tukey ao nível de $5 \%$ de probabilidade.

\section{RESULTADOS E DISCUSSÃO}

Na geração $R_{5}$, quatro dos 39 somaclones apresentaram resistência específica (nota 3) à brusone e, posteriormente, nas gerações $R_{6}$ e $R_{7}$, as reações variaram de 6 a 8 , indicando a quebra da resistência (Figura 1), enquanto a cultivar Cica8 em todas gerações apresentou nota 8 . A vulnerabilidade da resistência específica, sob alta pressão de doença, tem sido reconhecida (Ou, 1985). Embora a resistência específica tenha sido quebrada, a resistência parcial encontra-se em maior disponibilidade nas cultivares (Ribeiro do Vale et al., 2001).

Os somaclones $\mathrm{R}_{6}$ nas inoculações com cinco isolados monospóricos, provenientes de diferentes genótipos, pertencentes a quatro patótipos, apresentaram reações variáveis. Os somaclones e a cultivar CICA-8 apresentaram resistência completa para dois isolados ( $M t P y$ e EpPy) dos cinco testados. Para os demais isolados os somaclones apresentaram diferentes graus de brusone com notas variando de 1 a 7 . Os somaclones apresentaram reações resistentes e suscetíveis ao isolado proveniente do somaclone de Metica-1 ( $S c M t P y)$, enquanto a cultivar CICA-8 foi resistente. A cultivar CICA-8 mostrou reação incompatível ao isolado de Metica-1 (MtPy) e compatível ao isolado de CICA-8 (CiPy) (Tabela 1). Filippi et al. (1999) demonstraram a alta especificidade de isolados das cultivares Metica-1 e CICA-8, onde isolados de Metica-1 não foram virulentos à CICA-8 e vice-versa. Dois isolados, um de CICA-8 (CiPy) e outro do somaclone de CICA-8 (ScCiPy) apresentaram reações compatíveis para 29 somaclones, dos 39 testados.

A análise de variância do IRP calculado a partir do número de lesões $/ \mathrm{cm}^{2}$ mostrou que não houve interação significativa entre genótipos e isolados (Tabela 2). Resultados semelhantes foram obtidos nos estudos realizados com 


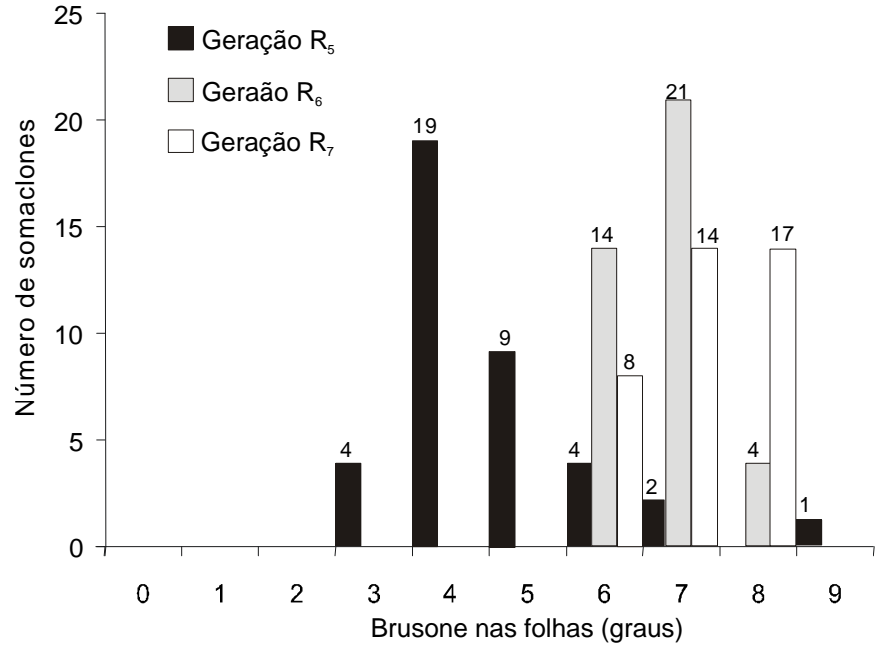

FIG. 1 - Distribuição de somaclones $\mathrm{R}_{5}, \mathrm{R}_{6}$ e $\mathrm{R}_{7}$ de arroz (Oryza sativa) CICA-8 de acordo com a reação à Pyricularia grisea nas folhas em viveiro de brusone. (A cultivar CICA-8 apresentou nota 8; Graus 0 a 3 = reação resistente; Graus 4 a 9 = reação suscetível).

somaclones de Basmati-370 (Araújo \& Prabhu, 2002). Por outro lado, Bonman et al. (1989) observaram grande interação entre genótipos e isolados para resistência parcial à brusone. Posteriormente, Roumen (1992) e Prabhu et al. (2002) demonstraram pequenas interações entre isolados e genótipos, indicando a natureza específica da resistência parcial. Nesses estudos a maior parte da variação foi explicada por efeitos principais de genótipos e isolados e somente uma pequena variação foi devida à interação. Estas pequenas interações sugerem que a resistência parcial é controlada por genes menores que operam na relação gene para gene. Este relacionamento no sistema poligênico com efeitos pequenos de cada gene foi postulado para ferrugem da folha da cevada por Parlevliet \& Zadocks (1977). No presente estudo, apesar das diferenças na agressividade dos isolados indicadas pelas notas 5 e 7, a interação não foi significativa. Estes resultados estão de acordo com Yeh \& Bonman (1986) que não obtiveram interação entre isolados e genótipos quando utilizaram cultivares com diferentes níveis de resistência parcial.

O IRP calculado a partir do número de lesões $/ \mathrm{cm}^{2}$ correlacionou com o IRP de severidade $(\mathrm{r}=0,98 ; \mathrm{P} \leq 0.01)$ (Figura 2). Estes resultados indicam a precisão, a consistência dos dados, e que a pressão de doença foi uniforme e adequada para determinação da resistência parcial. O número de lesões esporulativas é um dos parâmetros indicados para determinação da resistência parcial (Roumen, 1992; Bonman, 1992).

A seleção para resistência parcial à brusone no campo é difícil devido a presença de grande número de patótipos e de efeitos epistáticos de genes de hipersensibilidade sobre a expressão da resistência parcial. Para contornar este problema, a avaliação da resistência parcial é comumente realizada utilizando um patótipo virulento e um ou mais componentes de resistência parcial, para determinar as diferenças entre
TABELA 1 - Reação de somaclones $\mathrm{R}_{6}$ de arroz (Oryza sativa) CICA8 e da cultivar CICA-8 para cinco isolados de Pyricularia grisea sob condições artificiais de inoculação em casa de vegetação

\begin{tabular}{|c|c|c|c|c|c|}
\hline \multirow{2}{*}{ Genótipo } & \multicolumn{5}{|c|}{ 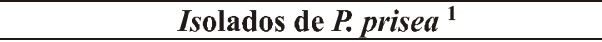 } \\
\hline & $M t P y$ & $C i P y$ & $S c M t P y$ & ScCiPy & $E p P y$ \\
\hline CNAI10562 $2^{2}$ & 0 & 7 & 5 & 5 & 0 \\
\hline CNAI10563 & 0 & 5 & 3 & 5 & 0 \\
\hline CNAI10564 & 0 & 5 & 5 & 5 & 0 \\
\hline CNAI10565 & 0 & 5 & 5 & 5 & 0 \\
\hline CNAI10566 & 0 & 5 & 5 & 1 & 0 \\
\hline CNAI10567 & 0 & 5 & 5 & 1 & 0 \\
\hline CNAI10568 & 0 & 5 & 5 & 5 & 0 \\
\hline CNAI10569 & 0 & 5 & 5 & 3 & 0 \\
\hline CNAI10570 & 0 & 5 & 5 & 3 & 0 \\
\hline CNAI10571 & 0 & 5 & 5 & 5 & 0 \\
\hline CNAI10572 & 0 & 7 & 5 & 3 & 0 \\
\hline CNAI10573 & 0 & 7 & 5 & 3 & 0 \\
\hline CNAI10574 & 0 & 7 & 5 & 3 & 0 \\
\hline CNAI10575 & 0 & 7 & 3 & 3 & 0 \\
\hline CNAI10576 & 0 & 5 & 3 & 1 & 0 \\
\hline CNAI10577 & 0 & 7 & 5 & 1 & 0 \\
\hline CNAI10578 & 0 & 5 & 5 & 5 & 0 \\
\hline CNAI10579 & 0 & 5 & 5 & 5 & 0 \\
\hline CNAI10580 & 0 & 5 & 1 & 5 & 0 \\
\hline CNAI10581 & 0 & 7 & 5 & 5 & 0 \\
\hline CNAI10582 & 0 & 7 & 5 & 5 & 0 \\
\hline CNAI10583 & 0 & 7 & 5 & 5 & 0 \\
\hline CNAI10584 & 0 & 5 & 1 & 3 & 0 \\
\hline CNAI10585 & 0 & 5 & 5 & 3 & 0 \\
\hline CNAI10586 & 0 & 5 & 5 & 7 & 0 \\
\hline CNAI10587 & 0 & 5 & 5 & 5 & 0 \\
\hline CNAI10588 & 0 & 5 & 5 & 5 & 0 \\
\hline CNAI10589 & 0 & 5 & 5 & 5 & 0 \\
\hline CNAI10590 & 0 & 5 & 5 & 5 & 0 \\
\hline CNAI10591 & 0 & 5 & 5 & 5 & 0 \\
\hline CNAI10592 & 0 & 1 & 5 & 5 & 0 \\
\hline CNAI10593 & 0 & 5 & 5 & 3 & 0 \\
\hline CNAI10594 & 0 & 5 & 3 & 5 & 0 \\
\hline CNAI10595 & 0 & 5 & 1 & 5 & 0 \\
\hline CNAI10596 & 0 & 5 & 3 & 5 & 0 \\
\hline CNAI10597 & 0 & 5 & 1 & 5 & 0 \\
\hline CNAI 10598 & 0 & 5 & 1 & 5 & 0 \\
\hline CNAI10599 & 0 & 5 & 3 & 5 & 0 \\
\hline CNAI 10600 & 0 & 5 & 1 & 5 & 0 \\
\hline CICA- $8^{3}$ & 0 & 7 & 3 & 5 & 0 \\
\hline Patotipo & ID-14 & II-I & IB-1 & IB-1 & IB-45 \\
\hline
\end{tabular}

${ }^{1}$ Graus de 0 a $3=$ resistentes e de 5 a $9=$ suscetíveis; ${ }^{3}$ Testemunha suscetível, não regenerada; $M t P y$ : isolado de Metica-1, CiPy: isolado de CICA-8, ScMtPy: isolado de somaclone de Metica-1, ScCiPy: isolado de somaclone de CICA-8, EpPy: isolado de Epagri 108;

${ }^{2}$ Número da entrada dos somaclones de Metica-1 no Banco Ativo de Germoplasma da coleção de trabalho do melhorista;

genótipos, porque a resistência parcial não é específica aos patótipos. Plank (1975) questionou a validade das conclusões baseadas nos testes realizados com um isolado na determinação da resistência parcial. Os resultados do presente trabalho, utilizando dois isolados virulentos, possibilitaram maior segurança na determinação do grau de resistência parcial nos somaclones.

Quatro somaclones apresentaram maior grau de 
Resistência parcial à brusone em somaclones da cultivar...

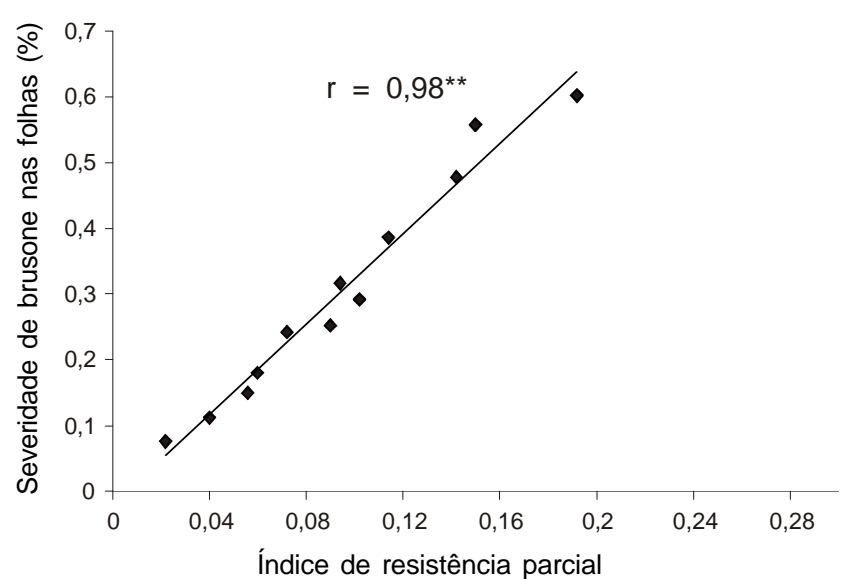

FIG. 2 - Correlação entre o índice de resistência parcial calculado com base no número de lesões $/ \mathrm{cm}^{2} \mathrm{e}$ a severidade à brusone em seis genótipos de arroz (Oryza sativa) inoculados com dois isolados de Pyricularia grisea.

resistência parcial à brusone do que a cultivar CICA-8 (Figura 3). A resistência completa das cultivares IR36 e IR50 para alguns patótipos de $P$. grisea foi idêntica porque os patótipos que infetam IR36 podem também infetar IR50 e vice-versa. Entretanto, estas cultivares diferiram quanto ao nível de resistência parcial, pois quando inoculadas com um patótipo compatível para as duas cultivares, a cultivar IR36 apresentou menor número e tamanho de lesões do que IR50 (Bonman, 1992). No presente trabalho, embora os quatro somaclones tenham apresentado resistência completa para alguns patótipos como o IB-1 do isolado de somaclone de Metica-1, ScMtPy (Tabela 1) mostrou também alto grau de resistência parcial. Estes somaclones podem ser utilizados como fontes de resistência parcial em cruzamentos com doadores de genes maiores de resistência vertical à brusone.

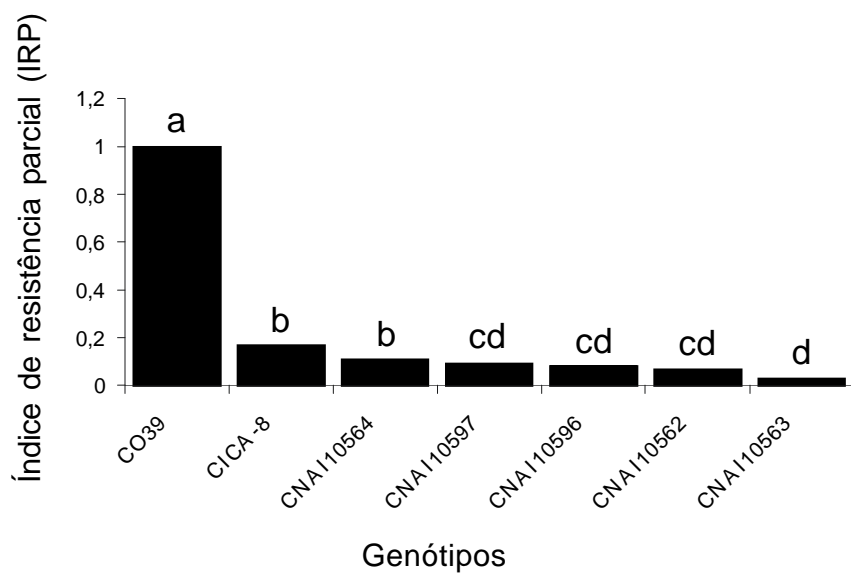

FIG. 3 - Índice médio de resistência parcial de cinco somaclones $\mathbf{R}_{6}$ de arroz (Oryza sativa) CICA-8 inoculados com dois isolados pertencentes aos patótipos II-I e IB-1 de Pyricularia grisea em casa de vegetação. Barras com a mesma letra não diferem entre si, pelo teste de Tukey a $5 \%$ de probabilidade. IRP $=$ Severidade de brusone nas folhas do genótipo em teste/Severidade da cultivar CO 39.

\section{AGRADECIMENTOS}

Ao Sr. Pedro Maurício Machado, técnico agrícola da Embrapa Arroz e Feijão, pela assistência na realização dos experimentos de campo.

\section{REFERÊNCIAS BIBLIOGRÁFICAS}

ARAÚJO, L.G. \& PRABHU, A.S. Progresso da brusone nas folhas e características agronômicas nas gerações avançadas de somaclones aromáticos da cultivar de arroz IAC 47. Fitopatologia Brasileira 26:625-632. 2001a.

ARAÚJO, L.G. \& PRABHU, A.S. Somaclones da cultivar de arroz aromático Basmati-370 resistentes à brusone. Pesquisa Agropecuária Brasileira 37:1127-1135. 2002.

ARAÚJO, L.G. \& PRABHU, A.S. Somaclones da cultivar de arroz Metica-1 resistentes à brusone. Fitopatologia Brasileira 26:366. 2001b. (Resumo).

ARAÚJO, L.G., PRABHU, A.S. \& FREIRE, A.B. Development of blast resistant somaclones of the upland rice cultivar Araguaia. Pesquisa Agropecuária Brasileira 35:357-367. 2000.

ARAÚJO, L.G., PRABHU, A.S. \& FREIRE, A.B. Variação somaclonal na cultivar de arroz IAC-47 para resistência à brusone. Fitopatologia Brasileira 22:125-130. 1997.

ARAÚJO, L.G., PRABHU, A.S., FILIPPI, M.C. \& OLIVEIRA, W.F. Variantes somaclonais da cultivar de arroz Bluebelle resistentes à brusone. Pesquisa Agropecuária Brasileira 36:801-808. 2001.

ATKINS, J.C., ROBERT, A.L. \& ADAIR, C.R. An international set of rice varieties for differentiating races of Pyricularia oryzae. Phytopathology 57:297-301. 1967.

BONMAN, J.M. Durable resistance to rice blast disease environmental influences. Euphytica 63:115-123. 1992.

BONMAN, J.M., BANDONG, J.M., LEE, Y.H., LEE, E.J. \& VALENT, B. Race specific partial resistance to blast in temperate Japonica rice cultivars. Plant Disease 73:496-499. 1989.

FILIPPI, M.C., PRABHU, A.S. \& LEVY, E.M. Differential compatibility of Pyricularia grisea isolates with some Brazilian irrigated rice cultivars. Fitopatologia Brasileira 24:447-450. 1999.

FUKUI, K. Sequential occurrence of mutation in a growing rice callus. Theoretical and Applied Genetics 65:225-230. 1983.

INTERNATIONAL RICE RESEARCH INSTITUTE. Standard evaluation system for rice. 3.ed. Los Baños, 1988.

LEUNG, H., BORROMEO, E.S., BERNARDO, M.A. \& NOTTEGHEM, J.L. Genetic analysis of virulence in the blast fungus Magnoporthe griseae. Phytopathology 78:1227-1233. 1988.

MANDAL, A.B., BIKASH, C., SHEEJA, T.E. \& CHOWDHURY, B. Development and characterization of salt tolerant somaclones in rice cultivar Pokkali. Indian Journal of Experimental Biology 38:7479. 2000 .

NOTTEGHEM, J.L. Cooperative experiment on horizontal resistance to rice blast. In: International Rice Research Institute. Blast and Upland Rice: Report and Recommendations From the Meeting for International Collaboration in Upland Rice Improvement. Los Baños. 1981. pp.43-51.

OU, S.H. Rice Disease. 2.ed. Kew. Commonwealth Mycological Institute. 1985. 
PARLEVLIET, J.E. \& OMMEREN, V.A. Partial resistance of barley to leaf rust Puccinia hordei. II. Relationship between field trials, microplot tests and latent period. Euphytica 24:223-303. 1975.

PARLEVLIET, J.E. \& ZADOKS, J.C. The integrated concept of disease resistance: A new view including horizontal and vertical resistance in plants. Euphytica 26:5-21. 1977.

PLANK, J.E. van der. Principles of plant infection. New York. Academic Press. 1975.

PRABHU, A.S., FILIPPI, M.C. \& CASTRO, N. Pathogenic variation among isolates of Pyricularia oryzae affecting rice, wheat and grasses in Brazil. International Journal of Pest Management 38:367-371. 1992.

PRABHU, A.S., GUIMARÃES, E.P., FILIPPI, M.C., ARAUJO, L.G. \& CUTRIM, V. dos A. Expression of resistance in rice hybrids to
Pyricularia grisea. Fitopatologia Brasileira 27:454-460. 2002.

RIBEIRO DO VALE, F.X., PARLEVLIET, J.E. \& ZAMBOLIM, L. Concepts in plant disease resistance. Fitopatologia Brasileira 26:577589. 2001.

ROUMEN, E.C. Small differential interactions for partial resistance in rice cultivars to virulent isolates of the blast pathogen. Euphytica 64:143-148. 1992.

XIE, Q.J., RUSH, M.C. \& CAO, J. Somaclonal variation for disease resistance in rice (Oryza sativa L.). In: Grayson, B.T., Green, M.B. \& Copping, L.G. (Eds.). Pest Management on Rice. London. Elsevier. 1990. pp.491-509.

YEH, W.H. \& BONMAN, J.E. Assessment of partial resistance to Pyricularia oryzae in six rice cultivars. Plant Pathology 35:319-323. 1986. 